\title{
Preoperative keratometry agreement: vector comparison between the IOLMaster 500, Galilei G2, and a Takagi autorefractor
}

Henry B. Wallace ${ }^{1}$, James McKelvie ${ }^{1,2}$, Sunny Sixiao Li ${ }^{1}$, Stuti L. Misra ${ }^{1}$

${ }^{1}$ Department of Ophthalmology, New Zealand National Eye Centre, Faculty of Medical and Health Sciences, University of Auckland, Auckland, New Zealand; ${ }^{2}$ Department of Ophthalmology, Auckland District Health Board, Auckland, New Zealand

\section{Abstract}

Introduction: Preoperative cataract assessment may involve multiple biometric instruments and it is important that clinicians are aware of the accuracy, limitations, and interchangeability of keratometry measurements conducted on these instruments.

Purpose: The purpose of the current study was to determine the agreement of keratometry magnitude and axis measurements obtained using three commonly used clinical keratometers.

Design of the study: Prospective, comparative study.

Materials and methods: One-hundred eyes of 100 prospectively enrolled patients listed for cataract phacoemulsification were recruited. Preoperative keratometry magnitude and axis measurements were obtained using the Galilei-G2 Dual Scheimpflug Analyzer (Ziemer Ophthalmic Systems AG, Port, Switzerland), IOLMaster 500, and Takagi ARKM-200 autokeratometer (Takagi Seiko Co., Ltd, Nagano-ken, Japan). Inter-device agreement in corneal spherical equivalent, corneal cylinder vectors, and corneal cylinder magnitude was assessed using the Bland-Altman method.

Results: One participant was excluded because of incomplete data. The Galilei-G2 reported the lowest mean keratometry $(43.96 \pm 1.71 \mathrm{D})$ and the IOLMaster reported the highest (43.99 $\pm 1.65 \mathrm{D})$. A single statistically significant difference occurred in

Correspondence: Dr. Stuti Misra, Department of Ophthalmology, Private Bag 92019, University of Auckland, Auckland, New Zealand.

E-mail: s.misra@auckland.ac.nz 
the corneal cylinder vector analysis between the IOLMaster 500 and the three-instrument pooled mean (mean difference $=-0.238 \mathrm{D}, \mathrm{P}=0.04$ ). No other statistically significant differences were observed for any instrument for any measured parameter. Excluding the vector difference analysis (range $=-0.175--0.238 \mathrm{D}$ ), mean differences between individual instruments and the three-instrument pooled mean did not exceed 0.025 $\mathrm{D}(\mathrm{P}>0.05)$.

Conclusion: The Galilei-G2, IOLMaster 500 (Carl Zeiss Meditec AG, Oberkochen, Germany), and Takagi ARKM-200 autokeratometer produce accurate keratometry and axis measurements that are comparable between instruments. The instruments could be used interchangeably in clinical practice in scenarios where accurate examinations cannot be obtained using one of the instruments.

Keywords: biometry, cataract, keratometry, refraction instruments, residual refractive error

\section{Persefahaman keratometri praoperasi: perbandingan vektor antara IOLMaster 500, Galilei G2, dan autorefractor Takagi}

\section{Abstrak}

Pengenalan: Penilaian katarak preoperatif mungkin melibatkan pelbagai instrumen biometrik dan adalah penting untuk doktor mengetahui ketepatan, batasan, dan penukaran pengukuran keratometri yang dilakukan pada instrumen ini.

Tujuan: Tujuan kajian semasa adalah untuk menentukan persefahaman magnitud keratometry dan pengukuran paksi yang diperoleh menggunakan tiga keratometer klinikal yang biasa digunakan.

Reka bentuk kajian: Prospektif, kajian perbandingan.

Bahan dan kaedah: Satu ratus seramai 100 pesakit yang didaftarkan secara prospektif yang disenaraikan untuk phacoemulsification katarak direkrut. Magnitud keratometri pra operasi dan ukuran paksi diperoleh dengan menggunakan Analyzer Scheimpflug Galilei-G2 (Ziemer Ophthalmic Systems AG, Port, Switzerland), IOLMaster 500, dan Takagi Seiko Co., Ltd, Nagano-ken, Jepun. . Persefahaman antara peranti dalam kornea silinder bulat yang setara, vektor silinder kornea, dan magnitud silinder kornea dinilai menggunakan kaedah Bland-Altman.

Keputusan: Satu peserta dikecualikan kerana data tidak lengkap. Galilei-G2 melaporkan keratometri min terendah $(43.96 \pm 1.71 \mathrm{D})$ dan IOLMaster melaporkan tertinggi (43.99 $\pm 1.65 \mathrm{D})$. Satu perbezaan statistik yang ketara berlaku dalam analisis vektor silinder kornea antara IOLMaster 500 dan min yang disatukan tiga 
instrumen (perbezaan bermakna $=-0.238 \mathrm{D}, \mathrm{P}=0.04$ ). Tiada perbezaan statistik lain yang diperhatikan untuk mana-mana instrumen untuk sebarang parameter yang diukur. Tidak termasuk analisis perbezaan vektor (julat $=-0.175--0.238 \mathrm{D}$ ), perbezaan antara instrumen individu dan instrumen gabungan tiga instrumen tidak melebihi $0.025 \mathrm{D}(\mathrm{P}>0.05)$.

Kesimpulan: The Galilei-G2, IOLMaster 500 (Carl Zeiss Meditec AG, Oberkochen, Jerman), dan Takagi ARKM-200 autokeratometer menghasilkan keratometri tepat dan ukuran paksi yang boleh dibandingkan antara instrumen. Instrumen ini boleh digunakan secara bergantian dalam amalan klinikal dalam senario di mana peperiksaan yang tepat tidak boleh diperoleh menggunakan salah satu alat.

Kata kunci: biometri, instrumen pembiasan, katarak, keratometri, kesilapan biasan baki

\section{Introduction}

Accurate keratometry is essential for intraocular lens (IOL) power and toricity selection, predetermining the precise IOL axis alignment prior to surgery, and the measurement of residual refractive error following cataract surgery. ${ }^{1}$ During IOL selection, keratometry errors of as minimal as one dioptre (D) may be associated with up to 2-4 lines of uncorrected visual acuity loss due to residual refractive error. ${ }^{1,2}$ Residual refractive error can have a significant detrimental impact on quality of life before and after cataract surgery. ${ }^{3,4}$ Patient expectations of outstanding visual outcomes following cataract surgery are increasingly common. ${ }^{4}$ These ever growing expectations place a premium on obtaining a high degree of accuracy during preand postoperative keratometry, which can significantly influence the IOL power selected and residual refractive error following surgery. ${ }^{3,5,6}$

It is not possible to get universal accurate and precise preoperative keratometry for every patient and often several keratometry instruments may be used for assessment prior to cataract surgery. Approximately $35 \%$ of patients undergoing cataract surgery have at least $1.00 \mathrm{D}$ of corneal astigmatism and will benefit from toric IOL implantation. ${ }^{7}$ Failure to implant toric lenses in these cases has the potential to reduce visual acuity by 1.5 lines per $\mathrm{D}$ of uncorrected corneal cylinder., ${ }^{8,9}$ The magnitude and axis of astigmatism must be accurately and reproducibly characterised in order to select the IOL toricity and axis of IOL implantation. ${ }^{10}$ The ability to accurately verify the magnitude, axis, and regularity of astigmatism on a second keratometer is a useful and reassuring strategy when considering implantation of a toric IOL. Without data to guide clinicians on the expected agreeability between instruments, interpreting differences in expected cylinder axis and magnitude can be a major issue when deciding on the most appropriate toric IOL to select to optimise the visual outcome following surgery. 
It is therefore important that all clinicians that assess refractive error are aware of the accuracy, limitations, and interchangeability of keratometry measurements conducted on different instruments and how these measurements may affect patient outcomes. The aim of the current study was to determine the agreement between the keratometry measurements of the Zeiss IOLMaster 500 (Carl Zeiss Meditec AG, Oberkochen, Germany), the Galilei-G2 Dual Scheimpflug Analyzer (Ziemer Ophthalmic Systems AG, Port, Switzerland), and the Takagi ARKM-200 autokeratometer (Takagi Seiko Co., Ltd, Nagano-ken, Japan), and to evaluate if the measurements could be used interchangeably when selecting IOL power or determining corneal astigmatic magnitude and axis.

\section{Materials and methods}

The current study was registered in the Australian New Zealand Clinical Trials Registry (ANZCTR) under registration number ACTRN12616001593426. Prior to surgery, all patients provided written informed consent and the current study was conducted in accordance with the Declaration of Helsinki, as well as the New Zealand National Ethics Advisory Committee guidelines. Formal approval was obtained from the New Zealand Health and Disability Ethics Committee (16/ CEN/132). Patients undergoing cataract surgery at the department of Ophthalmology at Greenlane Clinical Centre, Auckland District Health Board, New Zealand were prospectively enrolled for the current study. The current study aimed to recruit patients most representative of all patients undergoing cataract surgery in New Zealand. Exclusion criteria included pre-existing corneal pathology, previous ocular surgery, contact lens use, strabismus, and a postoperative target other than emmetropia. Enrolled patients underwent a full medical and ophthalmic history, and a complete ophthalmic slit lamp examination.

Keratometry for all patients was measured using the Zeiss IOLMaster 500, the Galilei-G2 Dual Scheimpflug Analyzer, and the Takagi ARKM-200 autokeratometer. The original equipment manufacturer for the Takagi branded instrument is Tomey Corporation (Aichi, Japan). All measurements for each patient were conducted on the same day, within a 30-minute interval, by an experienced technician in accordance with the instructions of the manufacturer, at the University of Auckland Ocular Imaging Unit. No eye drops were applied prior to keratometry and measurements were repeated, if required, until each keratometer reported a scan of adequate quality as determined by quality metrics reported by each keratometer. Simulated $\mathrm{K}$ values were extracted from the Galilei-G2 to ensure consistency in the corneal index of refraction utilised for corneal power calculations across all instruments $(n=1.3375)$. 


\section{Statistical analysis}

Statistical analysis was conducted using R Version 3.4.2 (R Foundation for Statistical Computing, Vienna, Austria). Data were tested for normality using the Wilks-Shapiro test. The following keratometric parameters were assessed: flat, steep, and mean keratometry, and corneal astigmatism.

Bland-Altman style analysis was used to calculate the difference between measurements from single instruments and the three-instrument pooled mean. Differences between measurements were then plotted against their mean along with lines representing the $95 \%$ limits of agreement. ${ }^{11}$ The $95 \%$ limits of agreement (mean difference $\pm 1.96 \times$ standard deviation) were used to define the confidence interval within which most differences between measurements from the pairwise comparisons will occur. To review the agreement, one-sample t-tests were conducted with the test value equal to zero. No statistical corrections for multiple analyses were performed.

Corneal astigmatism was compared using power vector analysis. ${ }^{12-15}$ The astigmatism value was converted to rectangular vectors $\mathrm{J} 0$ and $\mathrm{J45}$, using the following equations: $\mathrm{J} 0=-(\mathrm{C} / 2) \cos (2 \varnothing)$ and $\mathrm{J} 45=-(\mathrm{C} / 2) \sin (2 \varnothing)$, where $\mathrm{J} 0$ is the Jackson cross-cylinder axes at 90 and $180^{\circ}$, J45 is the Jackson cross-cylinder axes at 45 and $135^{\circ}, \mathrm{C}$ is the negative cylinder (flattest - steepest meridian), and $\varnothing$ is the axis of flattest meridian. Corneal cylinder magnitude alone as well as corneal vectors calculated according to Retzlaff were also compared to facilitate comprehension of the results for clinicians typically using these metrics. ${ }^{16}$

\section{Results}

One-hundred eyes (53 left) of 100 participants met the criteria for inclusion in the study. One participant was excluded because a reliable scan from the autokeratometer could not be acquired. The remaining 99 participants were included in the final analysis. The mean age of participants was $74.4 \pm 9.1$ years. Fifty-six eyes (56\%) were female. All measurements included in the statistical analysis individually passed all keratometer-reliability tests. Mean values for each parameter measured by each of the three keratometers are summarised in Table 1.

Mean differences for all analyses are summarised in Table 2. The largest mean difference occurred between the IOLMaster 500 cylinder vector and the mean cylinder vector of the three-instruments $(M D=-0.238 D, P=0.04)$. No other statistically significant differences were noted for any instrument for any measured parameter. No mean difference exceeded 0.025 D, excluding the vector difference analysis (range $=-0.175--0.238$ ). Bland-Altman plots for difference between individual instrument measurements and the three-instrument pooled means are demonstrated in Figure 1 (corneal spherical equivalent), Figure 2 (corneal power vectors), Figure 3 (corneal cylinder magnitude), and Figure 4 (Jackson cross-cylinders). 
Table 1. Summary values from three commonly used clinical keratometers

\begin{tabular}{|l|l|l|l|l|l|l|}
\hline & \multicolumn{2}{|l}{ Autokeratometer } & \multicolumn{2}{l|}{ IOLMaster 500 } & \multicolumn{2}{l|}{ Galilei-G2 } \\
\hline Parameter & Mean & SD & Mean & SD & Mean & SD \\
\hline Mean K (D) & 43.98 & 1.60 & 43.99 & 1.65 & 43.96 & 1.71 \\
\hline Flat K (D) & 43.60 & 1.60 & 43.59 & 1.65 & 43.57 & 1.72 \\
\hline Steep K (D) & 44.36 & 1.64 & 44.39 & 1.68 & 44.34 & 1.75 \\
\hline J0 (D) & -0.06 & 0.41 & -0.03 & 0.39 & -0.06 & 0.41 \\
\hline J45 (D) & 0.00 & 0.23 & 0.02 & 0.24 & 0.02 & 0.23 \\
\hline
\end{tabular}

D: dioptres; K: keratometry; J0: Jackson cross-cylinder, axes at 90 and $180^{\circ}$; J45: Jackson cross-cylinder, axes at 45 and $135^{\circ}$; SD: standard deviation

Table 2. Summary values from Bland-Altman analyses

\begin{tabular}{|l|l|l|l|l|l|l|}
\hline \multicolumn{1}{|c|}{ Analysis } & \multicolumn{1}{|c|}{ Instrument } & M. & P-value & T-value & $\begin{array}{c}\text { Lower } \\
\text { LoA }\end{array}$ & $\begin{array}{c}\text { Upper } \\
\text { LoA }\end{array}$ \\
\hline $\begin{array}{l}\text { Cylinder magnitude } \\
\text { difference }\end{array}$ & Autokeratometer & -0.014 & 0.654 & -0.450 & -0.631 & 0.603 \\
\hline $\begin{array}{l}\text { Cylinder magnitude } \\
\text { difference }\end{array}$ & Galilei & -0.013 & 0.712 & -0.370 & -0.722 & 0.695 \\
\hline $\begin{array}{l}\text { Cylinder magnitude } \\
\text { difference }\end{array}$ & IOLMaster 500 & 0.028 & 0.317 & 1.007 & -0.509 & 0.564 \\
\hline Flat keratometry & Autokeratometer & -0.008 & 0.708 & -0.375 & -0.407 & 0.392 \\
\hline Flat keratometry & Galilei & -0.001 & 0.966 & -0.043 & -0.551 & 0.549 \\
\hline Flat keratometry & OLMaster 500 & 0.009 & 0.717 & 0.363 & -0.468 & 0.486 \\
\hline J0 & Autokeratometer & -0.014 & 0.432 & -0.789 & -0.363 & 0.335 \\
\hline J0 & Galilei & -0.010 & 0.644 & -0.464 & -0.427 & 0.407 \\
\hline J0 & IOLMaster 500 & 0.024 & 0.171 & 1.379 & -0.316 & 0.364 \\
\hline J45 & Autokeratometer & -0.011 & 0.315 & -1.010 & -0.219 & 0.198 \\
\hline J45 & Galilei & 0.003 & 0.824 & 0.223 & -0.234 & 0.204 \\
\hline J45 & OLMaster 500 & 0.008 & 0.529 & 0.632 & -0.241 & 0.257 \\
\hline Mean keratometry & Autokeratometer & -0.015 & 0.388 & -0.867 & -0.348 & 0.318 \\
\hline Mean keratometry & Galilei & -0.008 & 0.750 & -0.320 & -0.491 & 0.475 \\
\hline Mean keratometry & IOLMaster 500 & 0.023 & 0.275 & 1.099 & -0.381 & 0.426 \\
\hline Steep keratometry & Autokeratometer & -0.022 & 0.397 & -0.850 & -0.525 & 0.481 \\
\hline Steep keratometry & Galilei & -0.015 & 0.658 & -0.443 & -0.659 & 0.629 \\
\hline Steep keratometry & IOLMaster 500 & 0.037 & 0.150 & 1.451 & -0.455 & 0.528 \\
\hline Vector difference & Autokeratometer & -0.210 & 0.063 & -1.882 & -2.390 & 1.969 \\
\hline Vector difference & Galilei & -0.175 & 0.140 & -1.488 & -2.472 & 2.121 \\
\hline Vector difference & IOLMaster 500 & -0.238 & 0.039 & -2.093 & -2.451 & 1.976 \\
\hline
\end{tabular}

LoA: 95\% limit of agreement; MD: mean difference between the instrument and the three-instrument pooled mean for a given analysis; vector difference: difference in corneal cylinder vectors according to Retzlaff ${ }^{16}$ 


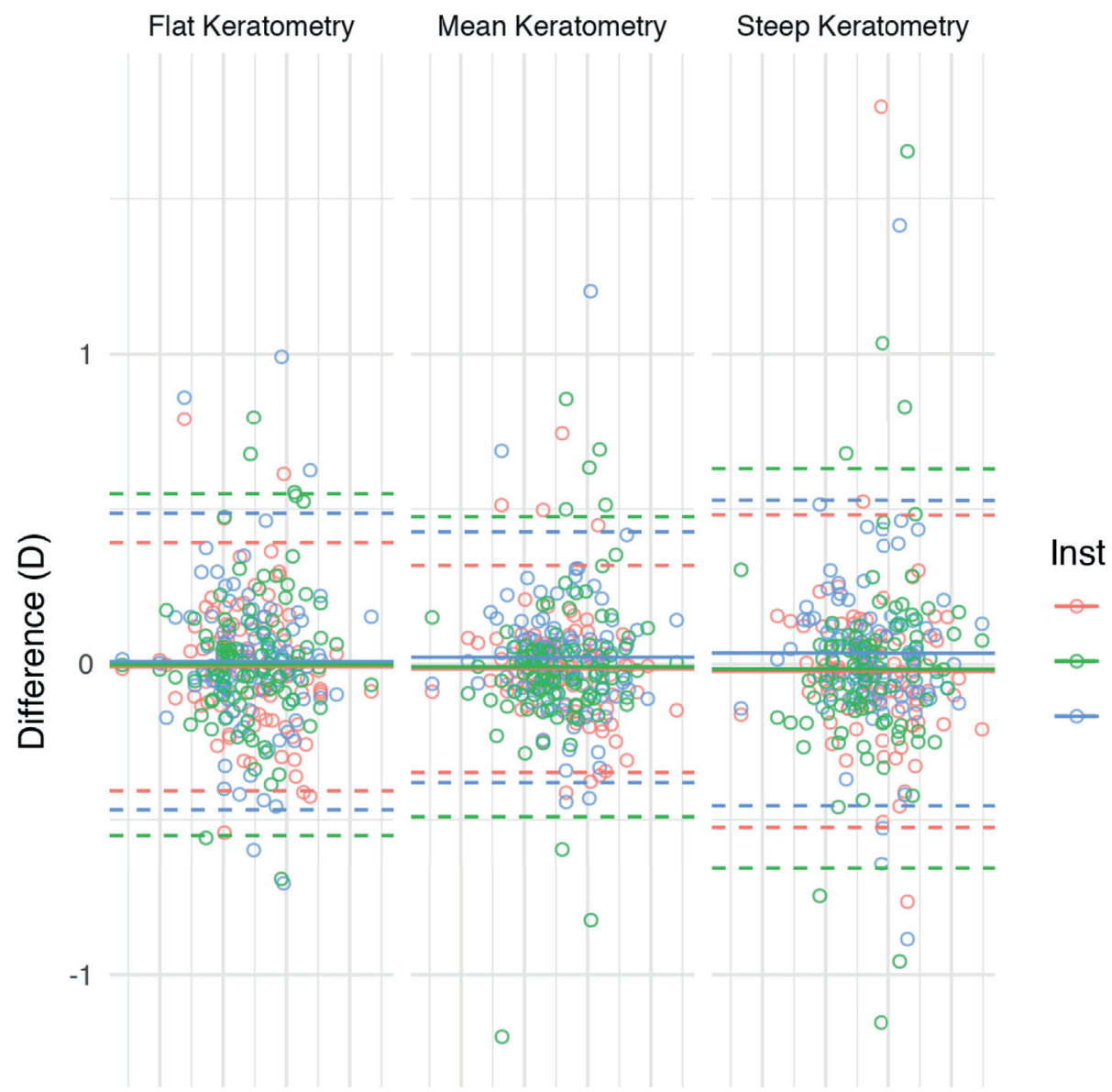

Fig. 1. Bland-Altman plots showing the agreement in flat, mean, and steep keratometry measurements (dioptres). Circles represent single measurements from single instruments in unilateral preoperative eyes of participants. Red: autokeratometer; blue: Galilei G2; green: IOLMaster 500. The central lines represent the mean of the difference between the instrument and the three-instrument pooled mean. Dashed lines represent $95 \%$ limits of agreement. 


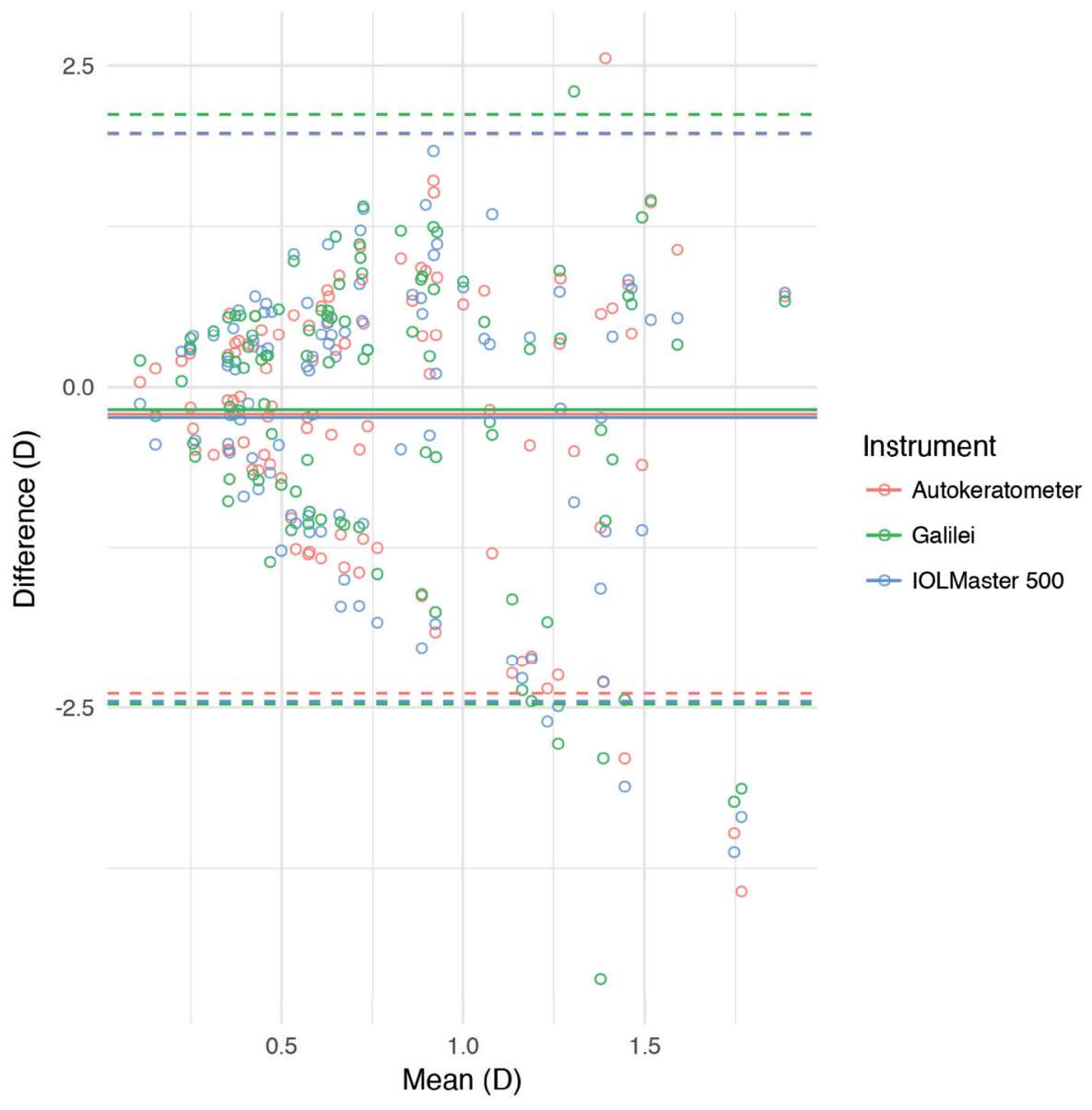

Fig. 2. Bland-Altman plot showing the vector difference in corneal cylinder between three commonly used clinical keratometers and the three-instrument pooled cylinder mean, calculated according to Retzlaff.16 Circles represent single measurements from single instruments in unilateral preoperative eyes of participants. Red: autokeratometer; blue: Galilei G2; green: IOLMaster 500. The central lines represent the mean of the difference between the instrument and the three-instrument pooled mean. Dashed lines represent $95 \%$ limits of agreement. 


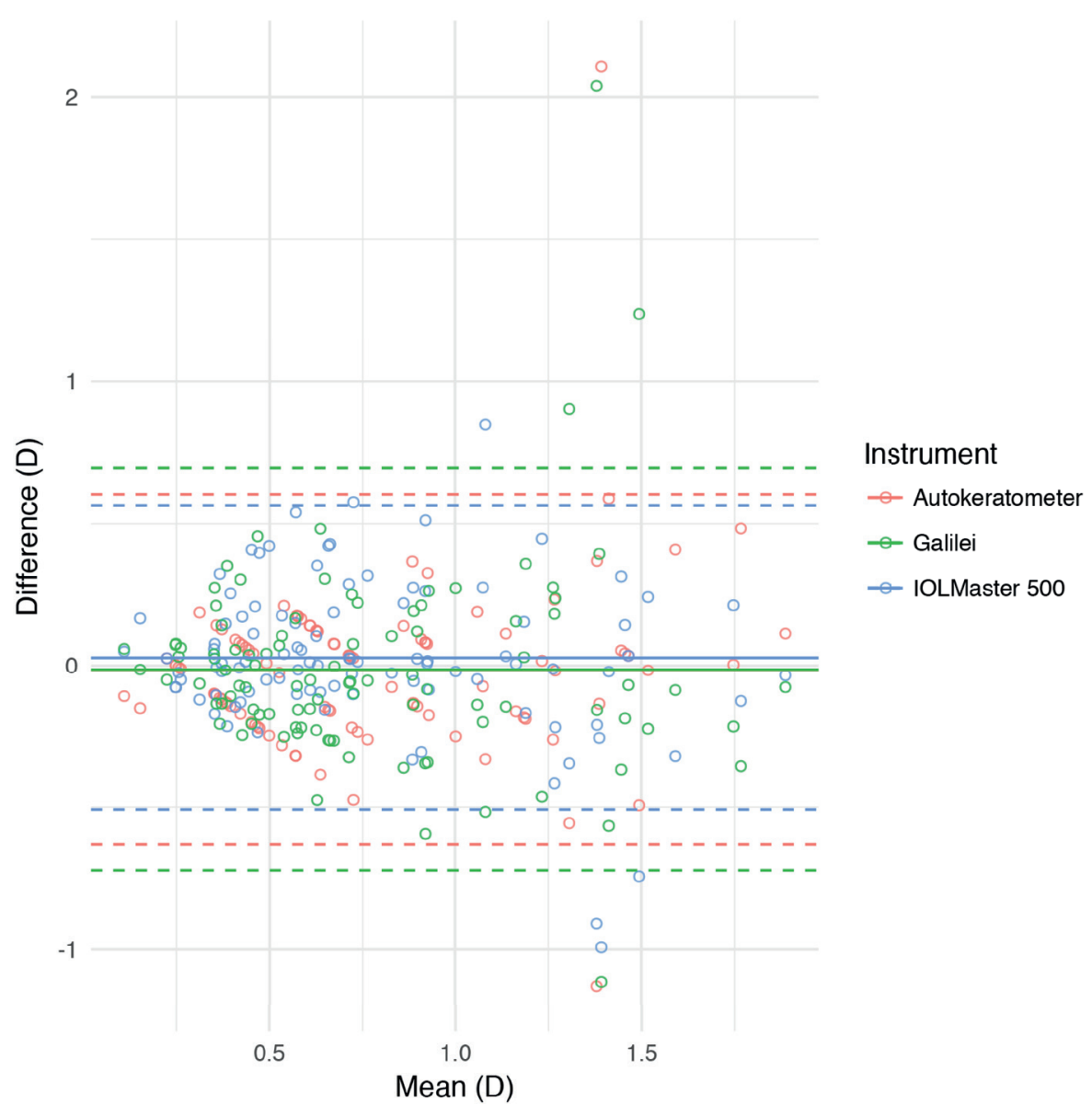

Fig. 3. Bland-Altman plot showing difference in cylinder magnitude between three commonly used clinical keratometers and the three- instrument pooled mean. Circles represent single measurements from single instruments in unilateral preoperative eyes of participants. Red: autokeratometer; blue: Galilei G2; green: IOLMaster 500. The central lines represent the mean of the difference between the instrument and the three-instrument pooled mean. Dashed lines represent $95 \%$ limits of agreement. 


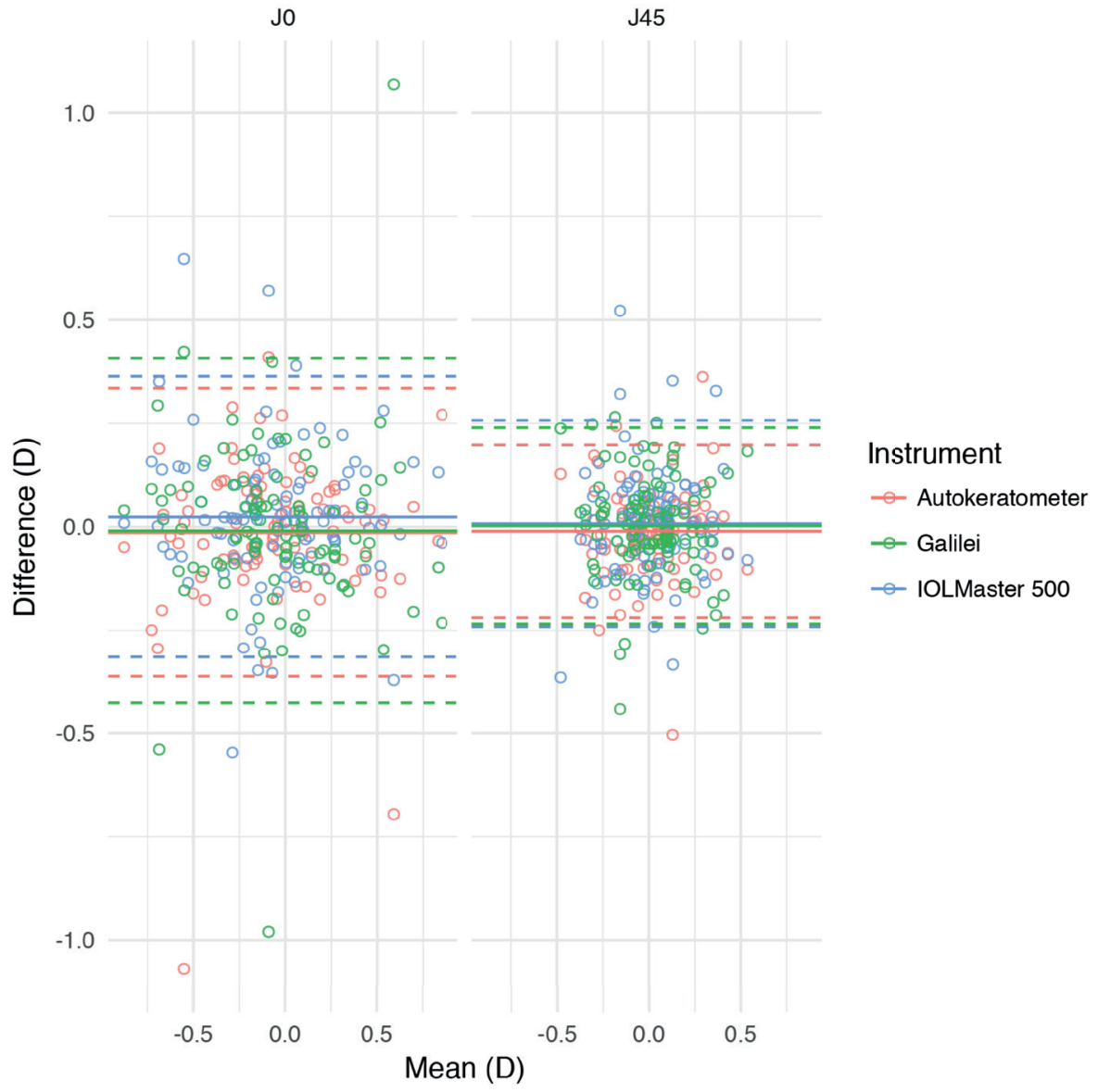

Fig. 4. Bland-Altman plots showing the agreement in J0 (Jackson cross-cylinder, axes at 90 and $180^{\circ}$ ) and $\mathrm{J} 45$ (Jackson cross-cylinder, axes at 45 and $135^{\circ}$ ). Circles represent single measurements from single instruments in unilateral preoperative eyes of participants. Red: autokeratometer, blue: Galilei G2, green: IOLMaster 500. The central lines represent the mean of the difference between the instrument and the three-instrument pooled mean. Dashed lines represent $95 \%$ limits of agreement. 
The Galilei-G2 had the widest 95\% confidence intervals for each of the keratometry parameters, except for the $\mathrm{J} 45$ analysis in which the IOLMaster had wider confidence intervals ( $\pm 0.249 \mathrm{D})$. The $95 \%$ limits of agreement for corneal spherical equivalent (mean keratometry) were all within $0.5 \mathrm{D}$. In the analyses of corneal cylinder, the largest limits of agreement did not exceed 2.30 D in the vector magnitude analysis (Fig. 2) and 0.75 in the cylinder magnitude analysis (Fig. 3).

\section{Discussion}

Accurate keratometry is essential to select an appropriately powered IOL to achieve optimised visual outcomes and patient satisfaction following cataract surgery. Most modern clinics that offer cataract surgery have several instruments capable of keratometry assessment and manufacturers typically claim high degrees of accuracy and repeatability despite different keratometry modalities. In cases where results from one instrument are suboptimal or of poor reliability, the use of an alternative source of keratometry is often required to ensure the IOL power selection is appropriate. An understanding of the accuracy and interchangeability of keratometry values obtained using different instruments is essential for clinicians to accurately predict and objectively quantify visual outcomes or surgically induced astigmatism in patients who may be difficult to measure using one modality alone.

The current study is the first to directly compare keratometry measurements obtained using the IOLMaster 500, the Galilei-G2 tomographer, and the Takagi ARKM-200 autokeratometer. After statistical analysis, no clinically significant differences were detected between any of the instrument pairs, for any measured parameter.

The Zeiss IOLMaster 500, although now superseded by a newer model, is still widely used in clinical settings for keratometry and axial length assessment prior to cataract surgery. This instrument uses 6 radial Purkinje images to calculate corneal curvature at a diameter of $2.5 \mathrm{~mm} .{ }^{17}$ Biometry measurements from the IOLMaster 500 have historically been considered gold-standard for the prediction of postoperative refractive outcomes. ${ }^{18}$ Autokeratometers also assume the cornea to be a convex mirror and also use the size and separation of infrared Purkinje images from the cornea to derive curvature. ${ }^{19}$ The autokeratometer in the current study used Purkinje images with 16 radial points, 8 points at $1.5 \mathrm{~mm}$ and 8 points at $3.0 \mathrm{~mm}$ radii from the corneal apex, to calculate curvatures at both $3 \mathrm{~mm}$ and $6 \mathrm{~mm}$ diameter (Tomey Corporation, 2017, unpublished data). For the current study, $1.5 \mathrm{~mm}$ radius measurements were used for comparison as they were most clinically relevant and directly comparable to the other two instruments. 
In contrast to the other two instruments, the Galilei-G2 tomographer combines information from a Placido disc and Scheimpflug images to determine anterior corneal curvature. ${ }^{1}$ In the current study, simulated keratometry indices were used (as opposed to the keratometry indices) in order to ensure consistency in the keratometric index of refraction utilised for all corneal power calculations across instruments ( $n=1.3375)$. The values labelled "Flat K" and "Steep K" in the Galilei-G2 interface refer to values calculated using the refractive index of the cornea $(n=1.376)$.

Each instrument in the current study uses a different method for alignment with the cornea. The autokeratometer automatically adjusts to a set reference distance before completing the measurement and the $\mathrm{G} 2$ requires manual alignment prior to completing a scan. In contrast, the IOLMaster 500 is the only instrument of the triad to that uses a telecentric optical configuration which allows distance-independent keratometry. The measurement radius of the IOLMaster 500 is therefore consistent, regardless of the distance between keratometer and eye.

The radius of measurement of an instrument is critical as it will affect its recorded keratometry values. Despite similar measurement methods, the IOLMaster 500 and autokeratometer have different radii of measurement $(r)$ at $1.25 \mathrm{~mm}$ and 1.5 $\mathrm{mm}$, respectively. In contrast, the Galilei-G2 has an arithmetic mean radius of measurement of $1.25 \mathrm{~mm}$ (range $=0.5-2.0 \mathrm{~mm}$ ) from its combined Placido disc and Scheimpflug camera technologies. ${ }^{1}$ The radius affects the data because keratometry values are generated from best-fit spheres, and if the points the sphere is fitted to are further apart, the radius of the sphere is inevitably larger, and the curvature of the sphere naturally flatter. These data are in keeping with the prolate nature of the cornea, where the steepest radii of curvature are located at the apex. This effect was evident in the current study. The IOLMaster 500, which takes measurements at $r=1.25 \mathrm{~mm}$, reported the steepest keratometry and astigmatism values, while the Galilei-G2, which takes 16 measurements between a $0.5 \mathrm{~mm}$ and $2.0 \mathrm{~mm}$ radius (arithmetic mean $=1.25 \mathrm{~mm}$ ), reported the flattest values. The autokeratometer $(r=1.5 \mathrm{~mm})$ reported data which were often in the middle of the other two data sets. Despite this trend, differences between the data sets were non-significant $(P>0.15)$.

Bland-Altman analysis demonstrated tight clustering of data around the line of no difference for all analyses as expected (Figs. 1-4). ${ }^{20-22}$ The only statistically significant mean difference observed in the current study occurred in the vector analysis of corneal cylinder (Fig. 2). The statistically significant difference may have occurred due to outliers resulting from small differences in axis measurement (range $7^{\circ}$ ) in patients with large amounts of corneal cylinder (mean $\left.=1.74 \mathrm{D}\right)$. The limits of agreement were generally narrow for all three instruments; however, the Galilei had the widest limits of agreement in 6 of 7 analyses. This may occur due to the Galilei's substantially different mechanism of measurement compared to the other two instruments. Figure 2 also demonstrates the increasingly large importance of accurate axis measurement as the corneal cylinder increases in magnitude and shows why it may be worthwhile for clinicians to verify corneal cylinder axes with 
a second instrument in some patients. In the current study, the consistency of astigmatic axis between instruments was also assessed using $\mathrm{J} 0$ and $\mathrm{J} 45$ vector analysis. ${ }^{12}$ No significant differences for these factors were noted with Bland-Altman analysis (Fig. 4). These instruments can therefore be used interchangeably for clinical applications where axis is critical, including selection of toric IOL in patients with pre-existing corneal astigmatism, and the measurement of surgically induced astigmatism. $^{21,22}$

With speed of measurement and ease of use, the autokeratometer is an ideal tool for swiftly measuring postoperative objective refractive outcomes. Achievement of predicted refraction is an objective, quantitative indicator of surgical outcomes, which are contributed to by a multidisciplinary team. Visual acuity alone is not an ideal indicator of refractive success as poor postoperative visual acuity will still occur in patients whose vision is limited by non-refractive pathology such as retinal or optic nerve disease despite successfully achieving the predicted refractive target. ${ }^{23-}$ ${ }^{26}$ Residual refractive error associated with keratometry measurement errors has been estimated at $8-8.59 \%$ of total residual refractive error. ${ }^{27,28}$ The clinically insignificant differences in the keratometry measurements from the three instruments in the current study show that the keratometry values from each of the instruments could be interchanged in IOL calculation formulae with relatively low impact on residual refractive error.

Limitations of the current study include the lack of repeatability data; however, the repeatability of these instruments have been demonstrated elsewhere..$^{17,29-32}$ Although newer versions of some of the instruments are available, the instruments analysed remain in widespread clinical use. The variation of each instrument from the pooled mean (of the three instruments) for each compared parameter is outlined in the $95 \%$ confidence intervals (Table 2, Figs 1-4). The autokeratometer had the lowest variation for the majority of analyses, lending further weight to the hypothesis that it is an accurate keratometer. Another consideration is that the participants in the current study were free from corneal pathology, which may limit generalisation of the results. Strengths of the current study are that it is a relatively large, prospective study. Additionally, measurements were acquired according to a predefined protocol by experienced operators.

The current study has shown that the keratometry data, including magnitude and axis, from the Galilei-G2, IOLMaster 500, and a Takagi autokeratometer are agreeable. These data could be used interchangeably in everyday clinical practice.

\section{Acknowledgements}

The authors wish to acknowledge Professor Charles McGhee for his mentorship and the provision of resources to support this research. 


\section{References}

1. Shirayama M, Wang L, Koch DD, Weikert MP. Comparison of accuracy of intraocular lens calculations using automated keratometry, a Placido-based corneal topographer, and a combined Placido-based and dual Scheimpflug corneal topographer. Cornea. 2010;29(10):1136-1138.

2. Holladay JT, Lynn MJ, Waring GO, Gemmill M, Keehn GC, Fielding B. The relationship of visual acuity, refractive error, and pupil size after radial keratotomy. Arch Ophthalmol. 1991;109(1):70-76.

3. Kandel H, Khadka J, Goggin M, Pesudovs K. Impact of refractive error on quality of life: a qualitative study. Clin Experiment Ophthalmol. 2017;45(7):677-688.

4. Do VQ, McCluskey P, Palagyi A, et al. Patient perspectives of cataract surgery: protocol and baseline findings of a cohort study. Clin Exp Optom. 2018;101(6):732-739.

5. Gomez ML. Measuring the quality of vision after cataract surgery. Curr Opin Ophthalmol. 2014;25(1):311.

6. Kirwan C, Nolan JM, Stack J, Moore TC, Beatty S. Determinants of patient satisfaction and function related to vision following cataract surgery in eyes with no visually consequential ocular co-morbidity. Graefe's Archive for Clinical and Experimental Ophthalmology. 2015;253(10):1735-1744.

7. Ferrer-Blasco T, Montés-Micó R, Peixoto-de-Matos SC, González-Méijome JM, Cerviño A. Prevalence of corneal astigmatism before cataract surgery. J Cataract Refract Surg. 2009;35(1):70-75.

8. Wolffsohn JS, Bhogal G, Shah S. Effect of uncorrected astigmatism on vision. J Cataract Refract Surg. 2011;37(3):454-460.

9. Atchison DA, Guo H, Charman WN, Fisher S. Blur limits for defocus, astigmatism and trefoil. Vision Res. 2009;49(19):2393-2403.

10. Waltz KL, Featherstone K, Tsai L, Trentacost D. Clinical outcomes of TECNIS toric intraocular lens implantation after cataract removal in patients with corneal astigmatism. Ophthalmology. 2015;122(1):39-47.

11. Bland JM, Altman DG. Measuring agreement in method comparison studies. Stat Methods Med Res. 1999;8(2):135-160.

12. Thibos LN, Wheeler W, Horner D. Power vectors: an application of Fourier analysis to the description and statistical analysis of refractive error. Optom Vis Sci. 1997;74(6):367-375.

13. Chan TC, Cheng GP, Wang Z, Tham CC, Woo VC, Jhanji V. Vector analysis of corneal astigmatism after combined femtosecond-assisted phacoemulsification and arcuate keratotomy. Am J Ophthalmol. 2015;160(2):250-255.

14. McLintock CA, McKelvie J, Gatzioufas Z, Wilson JJ, Stephensen DC, Apel AJ. Outcomes of toric supplementary intraocular lenses for residual astigmatic refractive error in pseudophakic eyes. Int Ophthalmol. 2018:1-8.

15. Oh E-h, Kim H, Lee HS, Hwang K-y, Joo C-K. Analysis of anterior corneal astigmatism before cataract surgery using power vector analysis in eyes of Korean patients. J Cataract Refract Surg. 2015;41(6):1256-1263.

16. Retzlaff J, Paden PY, Ferrell L. Vector analysis of astigmatism: adding and subtracting spherocylinders. J Cataract Refract Surg. 1993;19(3):393-398. 
17. Srivannaboon S, Chirapapaisan C, Chonpimai P, Koodkaew S. Comparison of ocular biometry and intraocular lens power using a new biometer and a standard biometer. J Cataract Refract Surg. 2014;40(5):709-715.

18. Kaswin G, Rousseau A, Mgarrech M, Barreau E, Labetoulle M. Biometry and intraocular lens power calculation results with a new optical biometry device: comparison with the gold standard. J Cataract Refract Surg. 2014;40(4):593-600.

19. Gutmark R, Guyton DL. Origins of the keratometer and its evolving role in ophthalmology. Surv Ophthalmol. 2010;55(5):481-497.

20. Mehravaran S, Asgari S, Bigdeli S, Shahnazi A, Hashemi H. Keratometry with five different techniques: a study of device repeatability and inter-device agreement. Int Ophthalmol. 2014;34(4):869-875.

21. Shirayama M, Wang L, Weikert MP, Koch DD. Comparison of corneal powers obtained from 4 different devices. Am J Ophthalmol. 2009;148(4):528-535.

22. Srivannaboon S, Chirapapaisan C, Chonpimai P. Comparison of corneal astigmatism and axis location in cataract patients measured by total corneal power, automated keratometry, and simulated keratometry. J Cataract Refract Surg. 2012;38(12):2088-2093.

23. Simon SS, Chee YE, Haddadin RI, Veldman PB, Borboli-Gerogiannis S, Brauner SC, et al. Achieving target refraction after cataract surgery. Ophthalmol. 2014;121(2):440-444.

24. Hilmi MR, Kamal KM, Azemin MZC, et al. Corneal curvature measurements utilizing a new sweptsource optical coherence tomography Tomey OA-2000 ${ }^{\circledR}$ and comparison With IOL Master ${ }^{\circledR} 500$ in pterygium patients. Sains Medika: Jurnal Kedokteran dan Kesehatan. 2018;9(1).

25. Hilmi MR, Khairidzan MK, Azemin ZC, Azami MH, Ariffin AE. Measurement of contrast sensitivity using the M\&S Smart System II compared with the standard Pelli-Robson chart in patients with primary pterygium. Makara Journal of Health Research. 2018.

26. Hilmi MR, Che Azemin MZ, Mohd Kamal K, Mohd Tamrin MI, Abdul Gaffur N, Tengku Sembok TM. Prediction of changes in visual acuity and contrast sensitivity function by tissue redness after pterygium surgery. Curr Eye Res. 2017;42(6):852-856.

27. Olsen T. Sources of error in intraocular lens power calculation. J Cataract Refract Surg. 1992;18(2):125129.

28. Norrby S. Sources of error in intraocular lens power calculation. J Cataract Refract Surg. 2008;34(3):368-376.

29. Meyer JJ, Gokul A, Vellara HR, Prime Z, McGhee CN. Repeatability and agreement of Orbscan II, Pentacam HR, and Galilei tomography systems in corneas with keratoconus. Am J Ophthalmol. 2017;175:122-128.

30. Crawford AZ, Patel DV, McGhee CN. Comparison and repeatability of keratometric and corneal power measurements obtained by Orbscan II, Pentacam, and Galilei corneal tomography systems. Am J Ophthalmol. 2013;156(1):53-60.

31. Kawamorita T, Uozato H, Kamiya K, Bax L, Tsutsui K, Aizawa D, et al. Repeatability, reproducibility, and agreement characteristics of rotating Scheimpflug photography and scanning-slit corneal topography for corneal power measurement. J Cataract Refract Surg. 2009;35(1):127-133.

32. Hamer CA, Buckhurst H, Purslow C, Shum GL, Habib NE, Buckhurst PJ. Comparison of reliability and repeatability of corneal curvature assessment with six keratometers. Clin Exp Optom. 2016;99(6):583589. 